\title{
Numerical simulation of crashworthiness parameters for design optimization of an automotive crash-box
}

\author{
Prabhaharan S. A. ${ }^{1}$ (D) G. Balaji ${ }^{2}$, and Krishnamoorthy Annamalai ${ }^{1,{ }^{*}}$ (D) \\ ${ }^{1}$ School of Mechanical Engineering, Vellore Institute of Technology, Chennai, India \\ ${ }^{2}$ ESI Group, India
}

Received: 9 January 2021 / Accepted: 2 November 2021

\begin{abstract}
Automotive manufacturers rely on rigorous testing and simulations to construct their vehicles durable and safe in all aspects. One such vital factor is crash safety, otherwise known as crashworthiness. Crash tests are conventional forms of non-destructive methods to validate the vehicle for its crashworthiness and compatibility based on different operating conditions. The frontal impact test is the most primary form of crash test, which focuses on improving passenger's safety and comfort. According to NHTSA, a vehicle is rated based on these safety criteria, for which automobile manufacturers conduct a plethora of crash-related studies. Numerical simulation aids them in cutting down testing time and overall cost endured by providing a reliable amount of insights into the process. The current study is aimed at improving the crashworthiness of a crash box in a lightweight passenger car, such that it becomes more energy absorbent in terms of frontal impacts. All necessary parameters such as energy absorption, mean crush force, specific energy absorption, crush force efficiencies are evaluated based on analytical and finite element methods. There was a decent agreement between the analytical and simulation results, with an accuracy of $97 \%$. The crashworthiness of the crash box was improved with the help of DOE-based response surface methodology (RSM). The RSM approach helped in improving the design of the crash box with enhanced EA \& CFE by $30 \%$ and $8.8 \%$ respectively. The investigation of design variables on the energy absorption capacity of the thin-walled structure was also done. For the axial impact simulations, finite element solver Virtual Performance Solution - Pam Crash from the ESI group is used.
\end{abstract}

Keywords: Crashworthiness / crash-box / thin-walled structure / energy absorbers / crash analysis

\section{Introduction}

Nowadays in the modern era where almost every people are in cities, towns or other sub-urban areas, use cars for their everyday commute. As a result of which a technological boom of globalization led to widespread of different ranges of automobile manufacturers across the globe towards developing nations like India and other countries. Every automobile manufacturer constantly innovates and iterates its models to catch up to their market trend. Before a vehicle approaches the end-user or the consumer, it involves rigorous testing and evaluations to satisfy different criteria. For which, a car composes of a number of systems and sub-systems to be tested with. One of the very principle factors in the testing is vehicle safety. Various organizations such as Global NCAP, NHTSA, Takata, ARAI etc., test the vehicles in their platform and

\footnotetext{
* e-mail: kannamalai@vit.ac.in
}

rate them in terms of passenger safety. In the view of passenger safety, a vehicle is evaluated for all conditions of crashes such as frontal, side, oblique and lateral impacts. The preliminary form of crash testing is undergone in terms of frontal impacts or collisions. The region of the vehicle experiencing the frontal impact can be classified into three zones namely, primary, secondary and tertiary crushing zones. Among which the primary crushing is the most crucial region wherein it contains various structures such as front members, side members, bumpers, and crash-boxes. These components are designed in such a way that, after involving in an impact they absorb the impending kinetic energy and deforms to dissipate it such that the effect of the collisions does not transcend to the passengers. The most vital component in determining the crashworthiness of the primary crushing zone is the crash-box, which is crushed initially due to the frontal impact loads. Also, the crash-box members are the main contributors in any crashworthiness study. Several types of research were devoted to the effectiveness of thin-walled structures. Abdullah [1] has 
given a comprehensive overview and summarization of methodologies \& research phases carried out concerning crash box structures. This gives us an outline of studies that have been performed towards these thin-walled structures to date. Broadly these research aspects are made with two kinds of crash box geometries. One is with the configuration of the crash box as thin-wall structure itself (i.e., without any in-fill materials [2]) and others with non- thin wall configurations (with appropriate in-filled materials [3]).

Sarage [4] performed an optimization study to enhance energy absorption of the thin-walled structures. Firstly, the performance of different crash box shapes was studied including square, rectangular and hexagonal with multiple material choices such as aluminum, steel, and CFRP. Better functioning configuration was further analyzed for optimization study by varying physical parameters such as thickness and by adding geometrical triggers to the crash box wall. It was found that hexagonal crash boxes with CFRP as the material with tapered side wall configuration performed better compared to others. Balaji [5] investigated the quasi-static axial loading response towards thinwalled hollow tubes with certain features such as V notches, grooves in improving the crashworthiness. They highlighted the significance of $\mathrm{V}$ notch initiators in the progressive crushing behavior of these structures. Pohlak [6] proposed the design of an extra frontal protective system for a car to meet the safety standards. To make the frontal protection system act better in terms of collision, improving the performance of energy-absorbing members through topology optimization was carried out. The quasistatic impact analysis was done for peculiar crash boxes such as Origami structures with intricate variations in origami patterns. The novel origami ending tubes portrayed better energy absorption capacity than other origami crash-boxes $[7,8]$. Multiple studies comprising of non-thin-walled crash box structures with fillers such as honeycomb, carbon fibers, auxetic lattices \& composite foams on improving the efficiency were extensively put forth by many researchers. Balaji [9] studied the crushing behavior of square honeycomb-filled crash boxes with carbon fiber inserts. They proposed that the expected outcomes for crashworthiness parameters such as IPF, SEA, CFE, and EA can be accurately obtained by varying the features of the number of carbon fiber inserts and the configuration of hexagonal honeycomb fillers. Simpson [10] focused on enhancing the crushing efficiency by improving the energy absorption rate through utilizing auxetic lattice structures in their design. The efficiency was significantly improved compared with empty tubes. Zhang [11] examined the design on conical thin-walled structures for its crashworthiness under oblique loading. This paper proposed a novel multi-cell tube with non-collinear conical angles to enhance the structural behavior under these loading conditions. It was inferred that the bi-tubular multi-cell cross-section of the MBCT (Multi-cell Bi-tubular Conical Tube) structure exhibited better crashworthiness towards oblique impacts ranging from $0^{\circ}$ to $30^{\circ}$.

Despite prevalent researches focused on numerous varieties of crash box structures with multiple design characteristics, thin-walled structures are popularly utilized as crash boxes in the production of automobiles.
Furthermore, there seemed to be scope for performing studies on these crash boxes which is still in practical usage. Hence our work was concentrated on improving the performances of these structures towards vehicle safety and for further advanced research like Reduced-Order Modelling. In this research work, the author has chosen a case study of a crash-box member (Courtesy: Toyota) supplied through NHTSA (National Highway Traffic Safety Administration) [12]. For the frontal impact, the crushing behavior of the crash-box is analyzed for different criteria. The ultimate aim is to derive a robust design, in terms of improved crashworthiness parameters, for which certain optimization methodologies have been proposed by earlier researchers. Hudec [13] carried out process optimization of T-joint and V-grooved welding based on sourcewire gas system. The performance efficiency was improved with the help of the DOE statistical method based on central composite design Hernández [14] proposed the method for lightweight parametric optimization of internal cellular structures based on additive manufactured parts. It involved optimization techniques based on Box-Behnken design of experiments and response surface methodologies. Yue [15] presented a multi-objective optimization, based on response surface methodology. The two-step optimization approach focused on developing an optimal conceptual design of a delta and canard wing configuration to achieve maximum lift and reduced drag. From the inference of literature, problems involving two factorial levels, widely adopted central composite design-based DOE. Hence in the present study optimization process involving Response Surface Methodology (RSM) with the central composite design was undergone. A multi-objective response optimization approach with design variables influencing the crash-box performance is maximized to optimize the responses. Later the robust design developed by the design of experiments is validated with the help of finite element simulations. The explicit crushing analyses and optimization were carried out to improve its crashworthiness and to develop a robust design for the crash box. For the numerical study FEM based solver PAMCRASH from the ESI group is utilized and for the RSM and successive multi-objective response optimization, commercial DOE platform Minitab is used.

\section{Crashworthiness parameters}

To assess the quality and performance of the crash boxes, certain key parameters have to be quantified to relate to the crashworthiness of those structures. Parameters include energy absorption, mean crush force, specific energy absorption, and crush force efficiencies. To obtain the solution towards these crashworthiness constants, certain empirical relations have been derived by previous researchers to aid the analyses.

Also, these equations are used for further validation purposes through experiments, numerical solutions, or FEM-based methods.

Energy absorption (EA) is the primary factor to be addressed when determining the crashworthiness of any structure. It can be acquired from the area under the 
force-displacement curve of the respective impact analysis [16]. Also, maximum internal energy absorption value can be considered as energy absorption. Maximum EA capacity is the desirable condition for any energy-absorbing structure.

$$
\mathrm{EA}(\mathrm{d})=\int_{0}^{\mathrm{d}} \mathrm{F}(\delta) \mathrm{d} \delta \mathrm{kJ}
$$

where $F=$ Crushing load, $\delta=$ maximum displacement, $d=$ crush length.

EA per unit mass of the specimen fetches Specific Energy Absorption (SEA). Similar to other parameters, higher SEA denotes better energy absorption capacity.

$$
\mathrm{SEA}=\frac{\mathrm{EA}}{\mathrm{m}} \frac{\mathrm{kJ}}{\mathrm{kg}}
$$

where ' $m$ ' is the mass of the crash-box structure.

Mean crushing load $\left(P_{m}\right)$ for this study can be extracted from the relations, given by Abramowicz and Jones [17] since it provided reliable outcomes for square and rectangular thin-walled geometries. The significance of assessing mean load is that it regulates the energy absorption capacity of the structure.

$$
\begin{aligned}
& \frac{P_{m}}{M_{o}}=52.22 \times\left[\frac{c}{h}\right]^{1 / 3} \\
& M_{o}=\left(\left[\sigma_{y} \times h^{2}\right] / 4\right) N
\end{aligned}
$$

where $h=$ thickness, $c=$ average side lengths, $M_{o}=$ Plastic bending moment, $\sigma_{y}=$ Yield stress of the material respectively.

The ratio of average crushing load to peak load results in crush force efficiency (CFE). CFE decides the quality of crushing behavior of the structure undergoing impact.

$$
C F E=\frac{P_{m}}{P_{\max }} \times 100 \%
$$

The value of CFE closer to the maximum indicates that the geometry has undergone ideal energy absorption nature with progressive deformation modes, which is more desirable in vehicle safety.

\section{Finite element model}

Explicit dynamic axial impact analysis is carried out for the finite element model of the Toyota crash box. For the numerical analysis explicit FEM-based solver PAM CRASH from the ESI group was used. The crash box geometry as shown in Figure 1, is of a squared cross-section with a slightly tapered wall configuration. The physical nature of the crash box can be characterized as a thinwalled structure bounded by four sheet metal components, with a top panel, two side boxes, and a base. Apart from that, the crash-box geometry contains some predefined corrugations and groove beads which yields better energy absorption for the structure. The external dimensions of the box are $(239) \times(172) \times(220) \mathrm{mm}$ respectively (refer

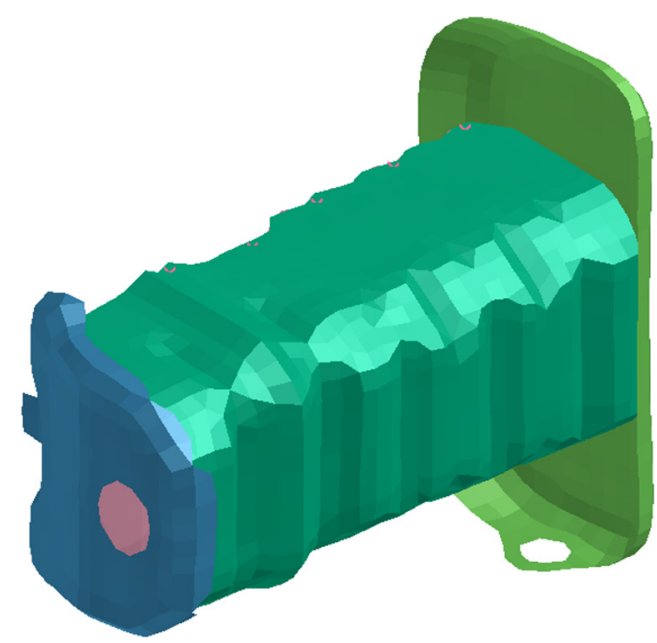

Fig. 1. Toyota crash-box structure.

Tab. 1). The meshing process was carried out in the VPS preprocessor package, Visual Mesh from ESI. For finite element modeling the geometry is modeled with thin shell elements with an average mesh size of $6 \mathrm{~mm}$. In the preprocessing phase, the material and contact card assignments have been followed the same method as adopted by Balaji [18]. Material type 103 that satisfies the iterative hill criterion for elastic-plastic condition to shell elements and type 101 null material shell conditions has been assigned to the rigid wall [19]. As the typical axial impact analysis involve the force distribution to be monitored between the two impacting bodies, contact type 34 is applied considering the rigid wall as master and crash box as slave geometry. Since the crash box undergoes multiple bending and folding mechanisms, self-contact type 36 was given to the crash box structure.

\subsection{Boundary conditions}

The rigid wall is set to collide with the crash box with an impact velocity of $10 \mathrm{~m} / \mathrm{s}$ in the longitudinal direction with a mass of $500 \mathrm{~kg}$. Base nodes of the crash box model are arrested to all DOFs since it's been fixed to the base. The static and dynamic friction properties between the bodies are taken to be 0.2 and 0.1 respectively. The material choice for the crash box and rigid wall structure was defined for steel with a young's modulus: $210 \mathrm{Gpa}$, Poisson's ratio: 0.3, material density: $7.85 \mathrm{E}-6 \mathrm{~kg} / \mathrm{mm}^{3}$. The mass is $1.92 \mathrm{~kg}$.

\subsection{Spot weld modeling}

The crash box structures involving multiple thin-walled sections are usually bounded with the spot-welds. In the critical locations of the crash box structure, where there is an adequate requirement of joints between the components, these spot welds are defined. Moreover, these spot weld definitions aids in undergoing proper crushing behavior during the simulations. In recent times, spot welds are utilized in certain crashworthiness studies and also, they are included as design variables in framing the 
Table 1. Dimensional details of default crash-box configuration.

\begin{tabular}{llllll}
\hline Sl no & Geometry & & \multicolumn{1}{c}{ Thickness in $(\mathrm{mm})$} & Dimensions in $(\mathrm{mm})$ \\
\hline \multirow{2}{*}{1} & Crash-box & Side wall 1 & Side wall 2 & Top panel & Base \\
& & 1.88 & 1.29 & 2.39 & 4.22 \\
2 & Rigid wall & Wall thickness & & & $239 \times 172 \times 220$ \\
& & 2.00 & & & $250 \times 310$ \\
\hline
\end{tabular}

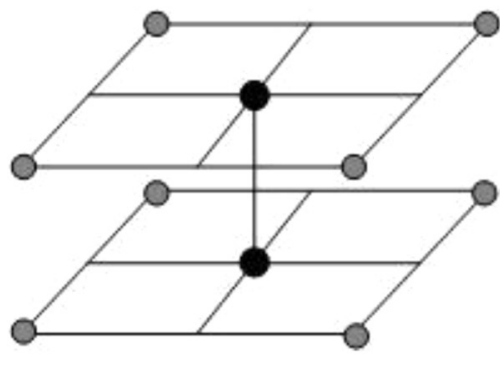

a

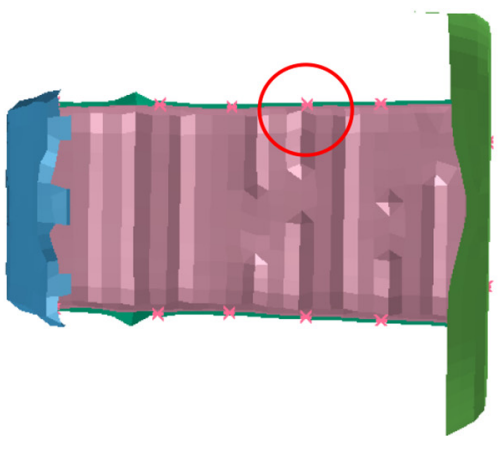

$\mathrm{b}$

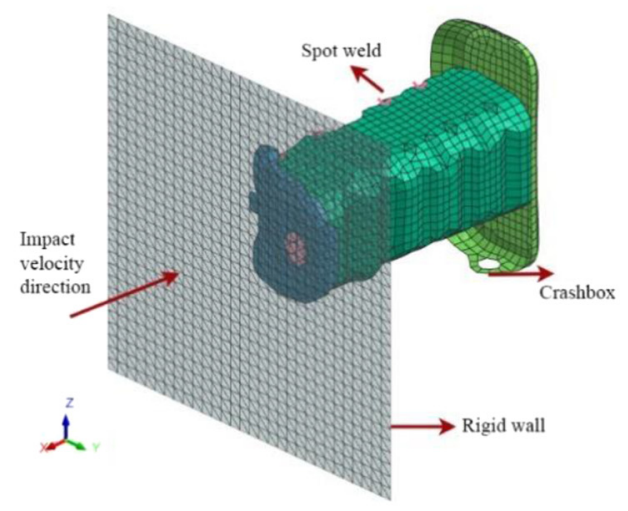

c

Fig. 2. (a) Rigid bar model; (b) crash-box with spot-weld definitions; (c) simulation setup.

optimization problems [17]. But limited works have been accomplished, involving spot weld definitions as design variable in crashworthiness optimizations [20]. Hence in the present study, spot weld definitions have been taken up as one of the design variables in the optimization process. The linkage between two bonding elements is constructed by defining a COG node as PLINK (Spot weld). The spot weld model can be considered as a rigid-bar model (as shown in Fig. 2), connecting pair of nodes, where the translational and rotational DOFs are coupled. Since the dimensions of the spot weld model are not taken into account, a rigid bar model is used here [20].

\section{Response surface methodology}

As the study is intended to improve the crash performance of these practically used thin-walled members, an optimization method is undergone to extract optimal crashworthiness parameters associated with the crash box structure. In the past, RSM has been successfully used to provide a quality outcome to create the robust design for enhancing the performance of the thin-walled structures. One could find a number of researches involving RSM in many optimization problems. In this methodology, several variables determining or influencing the response are tackled with and the objective of these experimental designs is to optimize the response. In a nutshell, the significance of RSM is that to optimize the response, an appropriate combination of levels of design variables are derived. The response surface optimization is carried out in the standard commercial package Minitab 18.0, which is a generic platform for the design of experiments. Towards optimizing the performance of our crash box model, $E A$ and $C F E\left(P_{m} / P_{\max }\right)$ are defined as response variables, subjected to spot-weld number $(S P W)$ and average thickness $(T H K)$ as design variables. For constructing the experimental design, the experiment is framed with the central composite design (CCD) to develop the response surface, since it is the most commonly used design for second-order models. The $2^{k}$ factorial design is fitted with a full-quadratic polynomial (as stated in Eq. (1)) to execute the experimental runs. Because they are accurate to be used as basis functions in response surface models as stated by Liu [21].

$$
y=\beta_{0}+\sum_{i=1}^{n} \beta_{i} x_{i}+\sum_{i=1}^{n} \beta_{i} x_{i}^{2}+\sum_{i=1}^{n} \sum_{j=1}^{m} \beta_{i j} x_{i} x_{j}+. .+\varepsilon .
$$

The response variables, $C F E$ and $E A$ are defined in terms of the function of design variables. To proceed further with the experimental design, the upper and lower bounds of the design variables have to be specified and that has to be involved in the objective function. Here the objective of our study is to maximize the $C F E$ and $E A$ parameters. The extremum of the design variables $S P W$ and $T H K$ defined as $n$ and $t$ respectively are $(8 \leq n \leq 14)$ and $(1.58 \leq t \leq 1.78)$ where $C F E(n, t)$ and $E A(n, t)$. The limits of the design variables are selected based on the criteria that they have to undergo proper crushing behavior under the stated boundary conditions. In the case of selection of the range of spot weld number, investigation of EA property on the spotweld number was undergone. The design by default had 8 spot welds, on increasing the number of spot welds beyond 14, the EA value for the current crash box model, followed a downward trend (as shown in Fig. 10a). Hence the spotweld range of 8 to 14 was selected. In the case of average thickness, the best variable 
range supporting the EA property as well as efficient crush performance without undergoing catastrophic effects were analyzed. The limits were fixed between 1.58 and 1.78.

Hence the optimization problem is defined as,

$$
\begin{aligned}
& \text { Maximize : } C F E(n, t) \\
& \text { Subjected to }:(8 \leq n \leq 14),(1.58 \leq t \leq 1.78) \\
& \text { (And) } \\
& \text { Maximize : } E A(n, t) \\
& \text { Subjected to }:(8 \leq n \leq 14),(1.58 \leq t \leq 1.78)
\end{aligned}
$$

The two governing conditions that are required to execute the CCD are the distance between axial points $(\alpha)$ and the number of center points $\left(n_{c}\right)$. The axial point distance $\alpha=1.414$ and $n_{c}=5$ are assumed for the calculations.

The experimental runs for the CCD are summarized in Table 2 .

$$
\begin{aligned}
C F E(n, t) & =P_{m} / P_{\max }(n, t) \\
& =-285+6.42(n)+357(t)-0.1576(n)^{2} \\
& -96.9(t)^{2}-2.08(n)^{*}(t)
\end{aligned}
$$

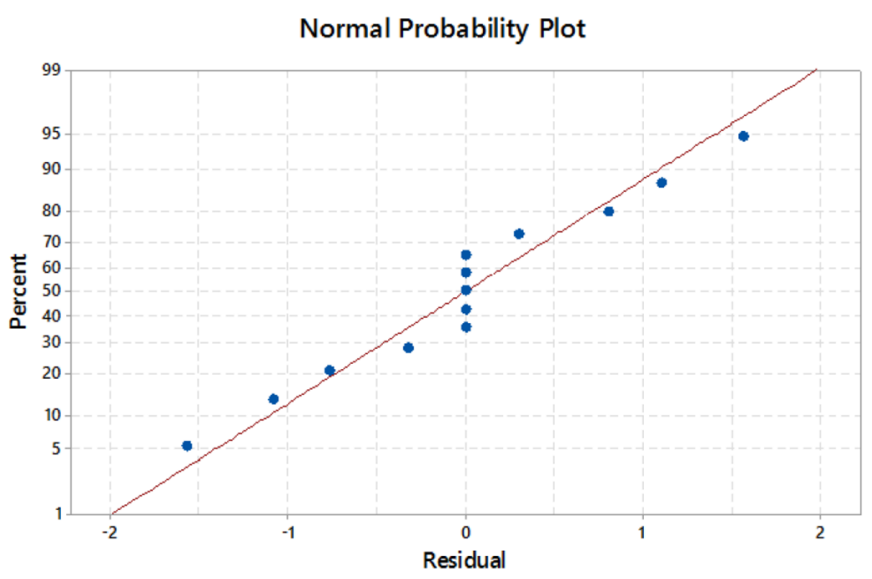

Fig. 3. Normal distribution plot of residuals.

$$
\begin{aligned}
E A(n, t) & =71.71-0.1735(n)-87.09(t) \\
& +0.008056(n)^{2}+27.750(t)^{2} \\
& +0.0167(n)^{*}(t) .
\end{aligned}
$$

The accuracy of the response surface model in predicting the responses are quantified based on the levels of $R^{2}$ and $R_{\text {adj }}^{2}$ values. It indicates the measure of improvement in the prediction of the regression formulation. They are calculated by the relation.

$$
\begin{gathered}
R^{2}=1-\frac{S S_{E}}{S S_{T}} \\
R_{a d j}^{2}=1-\left\{\frac{m-1}{n-1}\right\}\left(1-R^{2}\right) .
\end{gathered}
$$

According to the central composite design, the $2^{k}$ factorial model involved a totally 13 runs ( 4 cube points, 5 center points, and 4 axial points) for the DOE. Hence 13 finite element models are created according to the experimental design and are simulated to obtain the responses for $C F E$ and $E A$ respectively. By analyzing the experimental design, the regression equation in terms of uncoded coefficients for both the response variables is obtained, through the full quadratic polynomial (Eqs. (2) and $(3))$. The analysis of variance was performed with a confidence level of $95 \%$. Before arriving at the conclusions towards optimization problems, the distribution of residuals has to be examined. There are always possibilities of errors when involving response surface methodology and it has to be assessed to provide reliability towards the

Table 3. Values of $R^{2}$ and $R_{\text {adj. }}^{2}$

\begin{tabular}{lll}
\hline Response Surface Model & $R^{2}$ & $R_{a d j}^{2}$ \\
\hline CFE $(n, t)$ & 0.8433 & 0.7314 \\
EA $(n, t)$ & 0.994 & 0.990 \\
\hline
\end{tabular}

Table 2. DOE run order and respective CFE \& EA for each case from FE simulation.

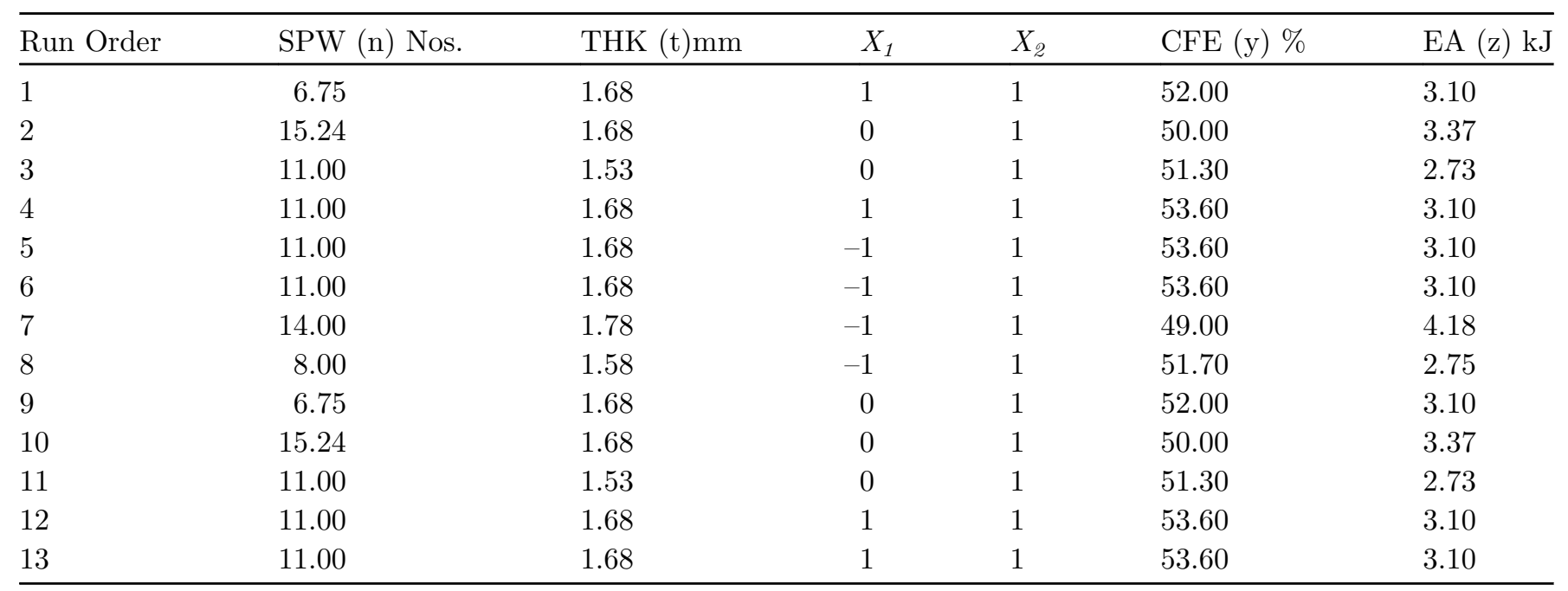



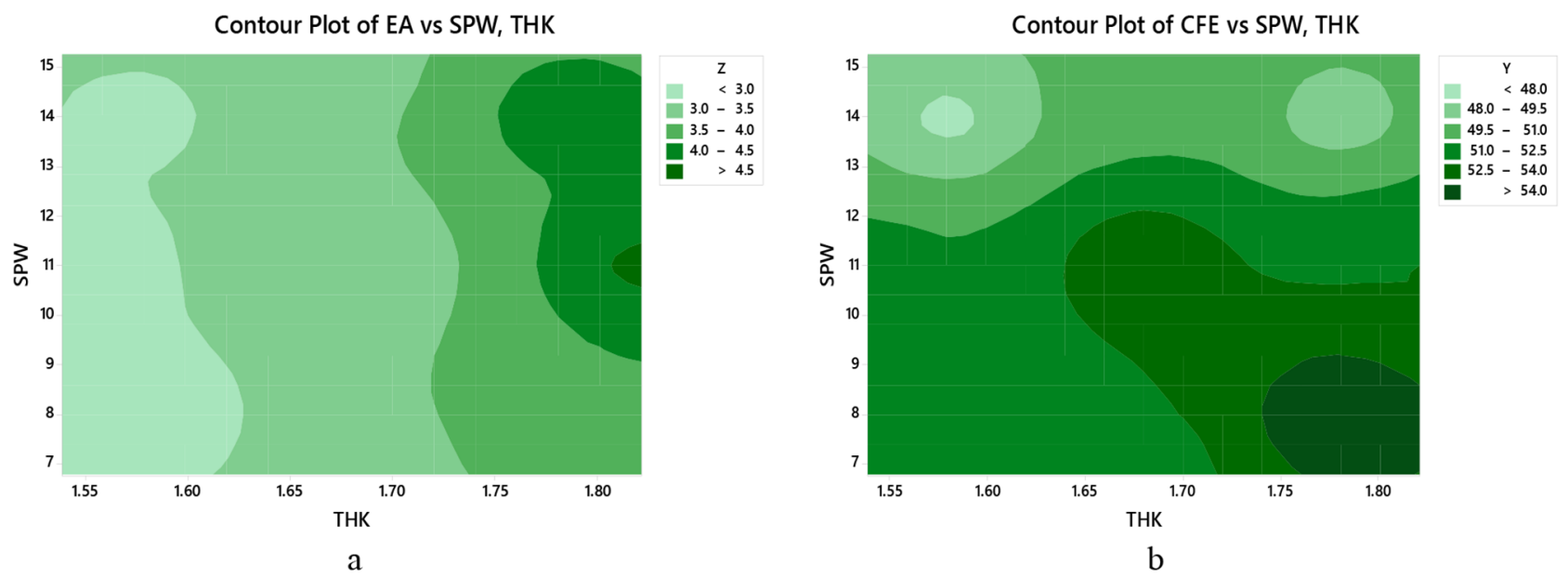

Fig. 4. Contour plot for the response surface of (a) EA; (b) CFE.

Table 4. Response optimizer output.

\begin{tabular}{lllll}
\hline \multirow{2}{*}{ Response variable } & \multirow{2}{c}{ Design variables } & THK $(t)$ & Response \\
\cline { 3 - 4 } & Desirability & $\mathrm{SPW}(n)$ & 1.82 & $53.9 \%$ \\
$E A(n, t)$ & 0.889 & 8.21 & 1.82 & $4.5 \mathrm{~kJ}$ \\
\hline
\end{tabular}

outcomes. Because to have a significant fit, the errors should be normally distributed preferably in a linear manner without any observable patterns. Residual values from the experiment must lie close to the regression line to consider the better prediction of the model. Figure 3 shows the normal distribution plot, exhibiting the linear normal distribution of errors, which fetches a significant fit for the experiment. Also, from the values of $R^{2}$ and $R_{\text {adj }}^{2}$ (see Tab. 3) the factors are high enough and contributed to the better fitness nature of the experiment according to classical response surface methodology theories. From the results of the experimental design, the response surfaces for both response variables ( $C F E$ and $E A$ ) are generated based on the analysis of variance and the respective outputs. Analyzing the response surfaces, using a response optimizer algorithm in-built in the Minitab platform, the optimal combination of our design variables $(n, t)$ in maximizing our response variables $(C F E, E A)$ are determined.

From the contour plots of the RS model, as shown in Figure 4, optimal design variables to maximize the response can be interpreted. The region from lighter to the darker area in the plot illustrates the maximization of the response variable. Desirable levels of our design variables lie in those darker regions. For example, in Figure $4 \mathrm{~b}$, the maximum $C F E$ is confined in the regions of $(1.74 \leq T H K \leq 180)$ and $(7 \leq S P W \leq 9)$ respectively. In such a way required combination to maximize the output can be extracted manually. But such manual extraction of optimal factors can be suitable for a single response variable. Since we have two response variables, the optimal solution has to be evaluated by correlating both the response surfaces. This process is demonstrated by the response optimizer algorithm, where it identifies the desirable combination or mix of design variables in maximizing one or more responses in other words (refer to Tab. 4), multi-response optimizations. The algorithm incorporates desirability functions to optimize multiple responses, simultaneously. The desirability value represents the proximity of the response variables to the ideal value. From the response optimizer output as shown in Table 4 , with desirability of 0.88 the algorithm predicted $S P W(n): 8$ and $T H K(t): 1.82$ respectively to maximize the $C F E(n, t)$ and $E A(n, t)$. The outcomes from the DOE procedure are extensively studied and are validated with the help of finite element solutions which are discussed in the upcoming sections.

\section{Results and discussions}

\subsection{Explicit axial impact analysis}

Before validation of the optimization results from the analytical solution, the default configuration of the crashbox as specified by NHTSA is conducted for low-speed axial impact analysis, so that its crashworthiness parameters can be used to benchmark with the results of the optimized crash-box design. Taking into account the design variables, the default configuration possesses 14 spot-welds and an average thickness of $1.58 \mathrm{~mm}$. The model is executed for the finite element analysis with the appropriate boundary conditions as specified in the previous section. The crash simulation is undergone in a PC equipped with core i5 dualcore processors and a 16GB of RAM. The average simulation time for each case was computed around $95 \mathrm{~s}$, 


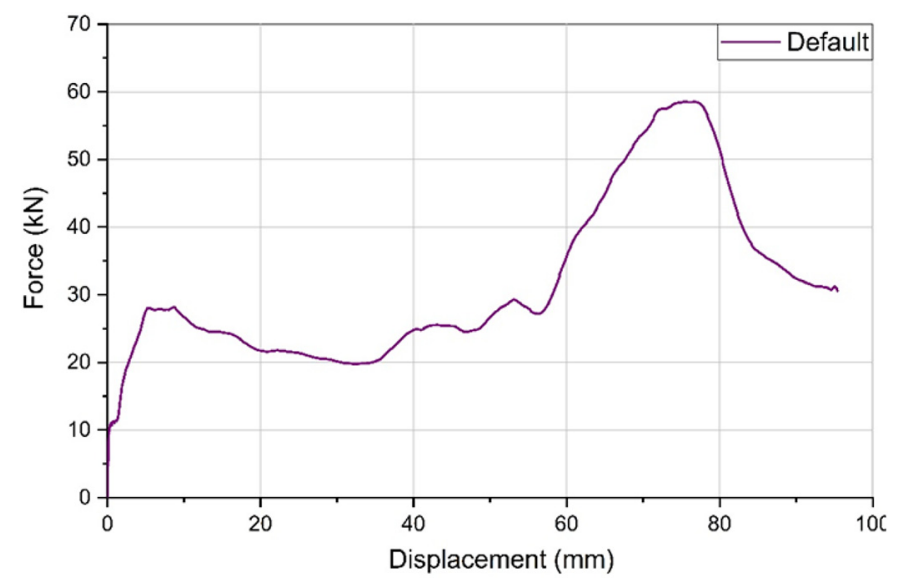

Fig. 5. F-S curve of default crash-box.

Table 5. Analytical vs simulation results validation.

\begin{tabular}{lllll}
\hline Result & $P_{m}(\mathrm{kN})$ & EA $(\mathrm{kJ})$ & CFE $(\%)$ & Error $(\%)$ \\
\hline Analytical & 29.44 & 3.02 & 51.70 & 2.57 \\
Simulation & 31.00 & 2.93 & 50.40 & \\
\hline
\end{tabular}
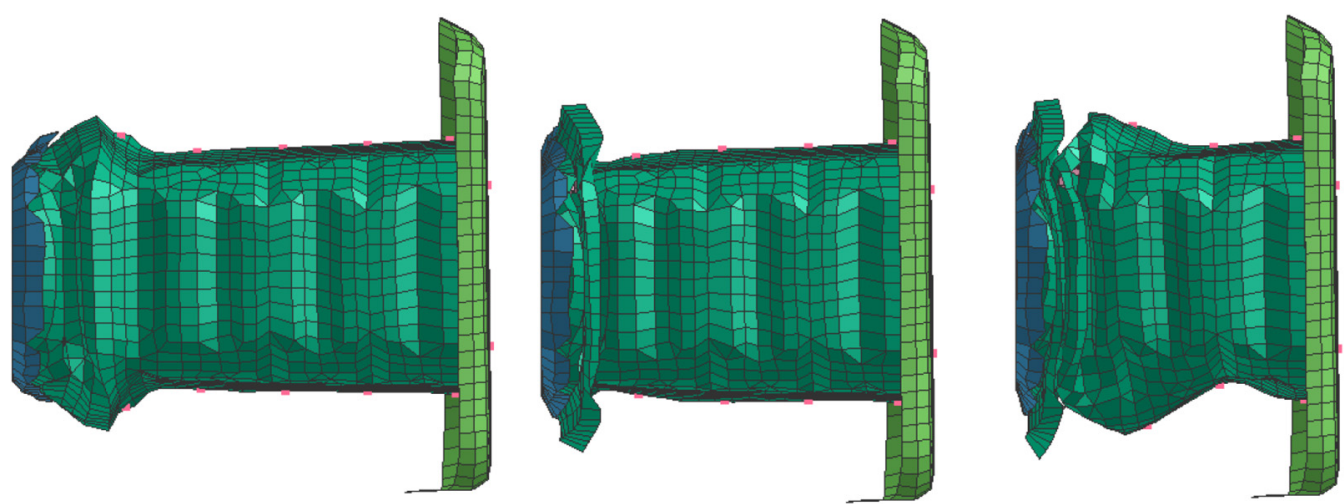

Fig. 6. Deformation modes of default crash-box.

for the finite element model with 7000 thin shell elements. The crash situation is executed with an axial impact velocity of $10 \mathrm{~m} / \mathrm{s}$. The respective $F-S$ curve from the nodal time history of COG, belonging to the rigid wall was referred for the crashworthiness study as shown in Figure 5. Generally, in standard crash-box structures, the crushing is initiated by a huge peak force followed by a gradual decrease in load and the trend remains constant till the end of the displacement event. In those cases, the initial peak force is maximum which reduces the crush force efficiency. Moreover, since the area under the F-S curve determines the total energy absorption, it also leads to a reduction in internal energy absorption. Therefore crash-box designers tend to reduce the initial peak force to the possible extent. Also, the automotive manufacturers aim to design their crash-boxes in such a way that, the peak force occurs towards the right extreme of the $\mathrm{F}-\mathrm{S}$ curve. By doing so improves the performance of the system and results in progressive crushing. On the other hand, the area under the curve is reasonably increased thereby leading to an increase in energy absorption. Hence by analyzing the trend of the $\mathrm{F}-\mathrm{S}$ curve of our finite element model, it can be seen that the initial peak force is reduced and the peak is shifted to the right end of the curve. From the deformation modes, the progressive crushing behavior of the model is exhibited as represented in Figure 6.

Having the simulation outcomes, the crashworthiness parameters are assessed both with the help of analytical results and the FE results. From Table 5, it can be inferred that the results from the simulated data lie in close alignment with the analytical calculations. 


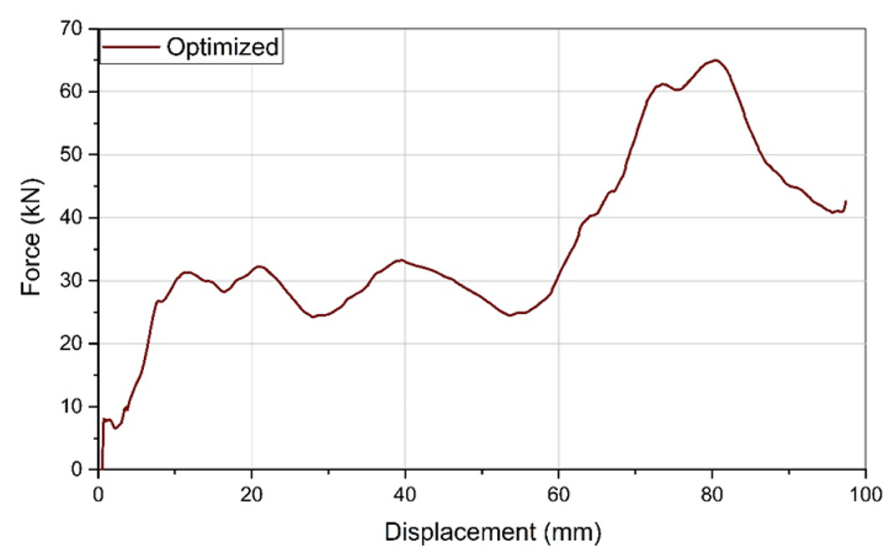

Fig. 7. $F-S$ curve of optimized crash-box.

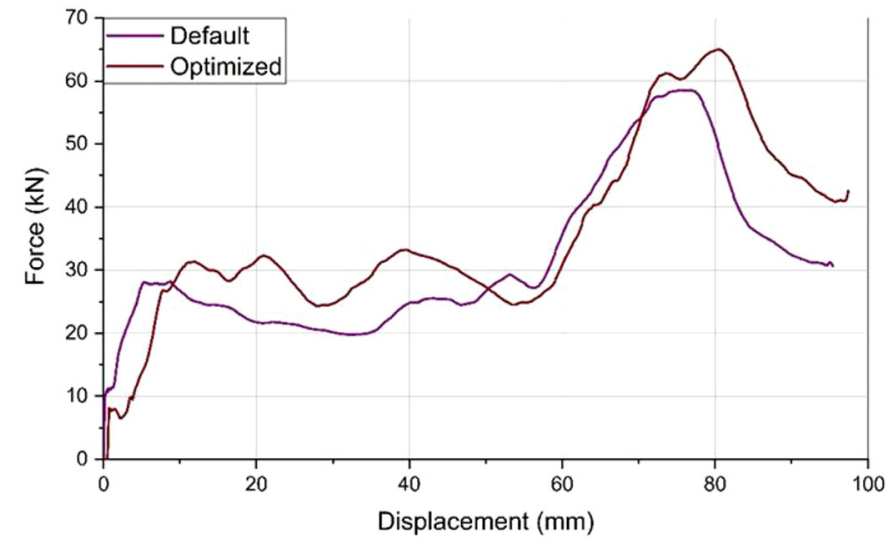

Fig. 9. $F-S$ curve comparison between default \& optimized crash-box.
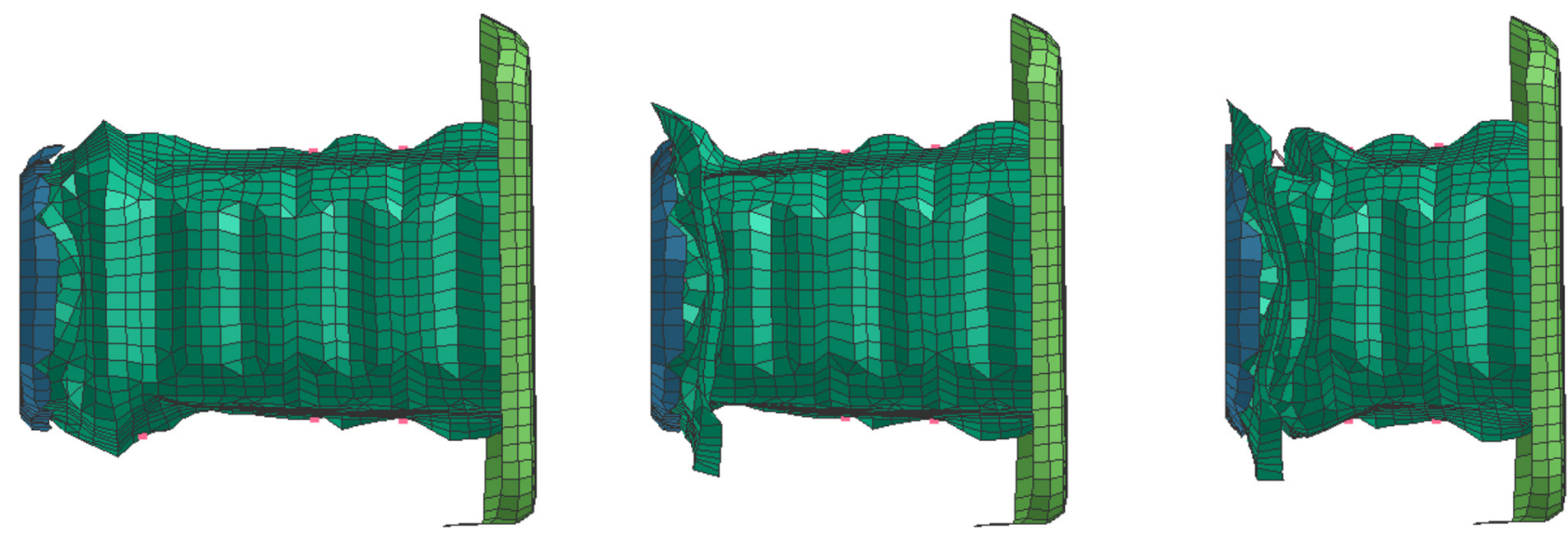

Fig. 8. Deformation modes of optimized crash-box.

Table 6. RSM vs simulation results validation.

\begin{tabular}{lllll}
\hline Result & $P_{m}(\mathrm{kN})$ & EA $(\mathrm{kJ})$ & CFE $(\%)$ & Error $(\%)$ \\
\hline RSM & 37.70 & 4.50 & 53.90 & \\
Simulation & 35.90 & 4.61 & 55.30 & 2.53 \\
\hline
\end{tabular}

\subsection{Validation of the optimization results}

After performing the preliminary analysis for the default configuration of the crash-box, the impact analysis is carried out for the optimized crash-box as well. Then the performance of the optimized crash-box is benchmarked with the previous configuration and is studied whether the optimized variant is crashworthy or not. From extracted results of the RSM procedure, the design variables $S P W: 8$ and THK: 1.82 are defined for the numerical simulation. By modifying the physical parameters of the crash-box based on the RSM outputs, the mass of the specimen increased from $1.92 \mathrm{~kg}$ to $2.06 \mathrm{~kg}$. As it is observed there is only a $6.7 \%$ percentage increment in the overall weight of the body, so it is suggested not to add more mass than the acceptable levels.
The finite element simulation results, on comparing with the RSM outcomes, yielded better alignment as seen in Table 6. By examining the FE results of the optimized crash-box geometry, one could observe that there is a slight increase in the initial peak force as well as $P_{\max }$ as shown in Figure 7. Subsequently, the mean crushing load $P_{m}$ was also incremented to $35.9 \mathrm{kN}$. Evidently, as these parameters were leveled up, the area under the $F-S$ curve increased compared to the default crash-box $F-S$ curve (refer Fig. 9). Automatically since there is a rise in the area under the force displacement curve, the energy absorption rate was also incremented to $4.6 \mathrm{~kJ}$. The deformation pattern contained much resolution towards the progressive folding and bending mechanisms as shown in Figure 8, compared to the default structure. Also, by reducing the number of spot-welds, significantly the overall stiffness of 


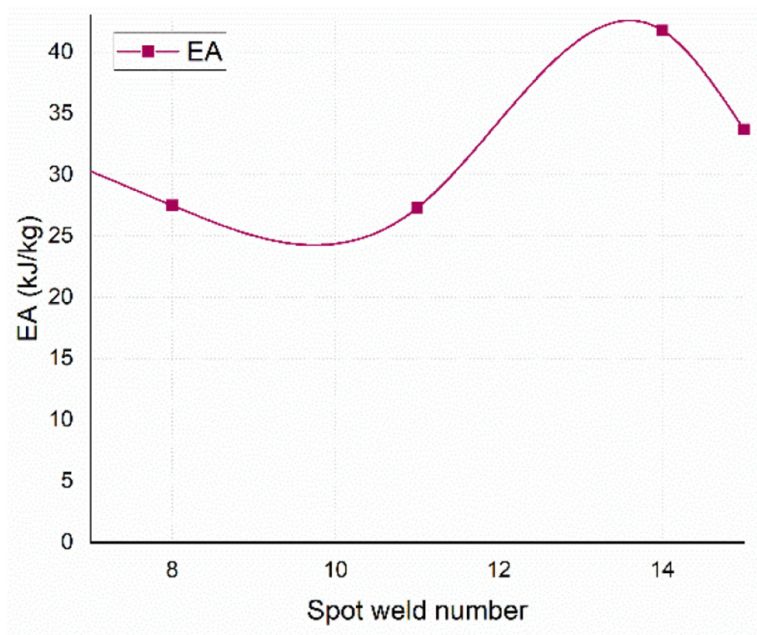

(a)

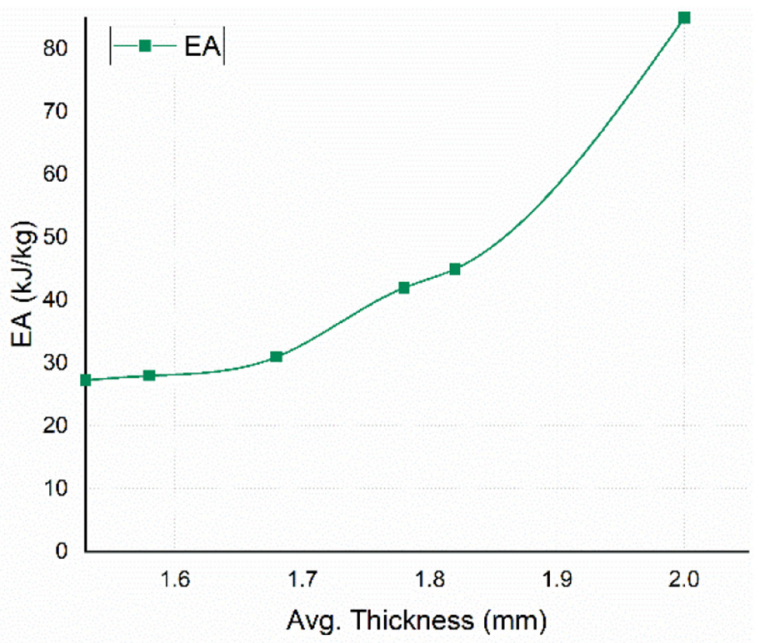

(a)

Fig. 10. Effect of design variables on EA. (a) Spot-weld vs EA; (b) Avg. Thickness vs EA.

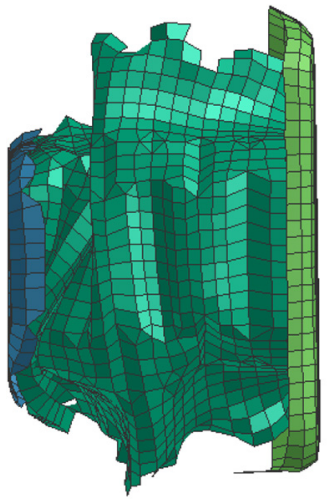

(a)

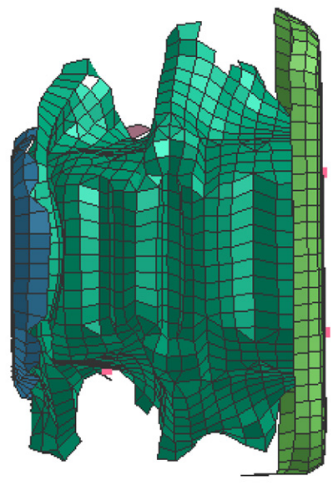

(b)
Fig. 11. Failure of the crash-box structure.(a) Deformation with 8 spot-welds \& avg. THK 2.00; (a) Deformation with 14 spotwelds \& avg. THK 2.00 .

the structure is reduced allowing for a good deformation pattern. On concentrating the SEA capacity of both the models, the SEA yielded better outcomes. The specific energy absorption capacity was increased from $1.52 \mathrm{~kJ} / \mathrm{kg}$ to $2.23 \mathrm{~kJ} / \mathrm{kg}$. Verifying the nature of crashworthiness parameters, it can be concluded that, the optimized crashbox as a result of the response surface model had better crushing behavior and performance when dealt with the default configuration.

\subsection{Effect of design parameters on energy absorption}

The ultimate focus of every study on energy-absorbing members such as thin-walled structures is on maximizing the energy absorption capacity [1]. From the review of the simulation results, from Figure 10a, it could notice that the spot-weld number influences greatly in the energy absorption capacity of the structure. On one way, the EA gradually develops by adding the number of spot-welds.
Beyond the critical limit, the structure becomes too stiff, to absorb the impending impact energy, and hence the EA drastically reduces beyond that critical limit. As the number of spot-welds decreases, beyond critical limit, it results in a gradual increase in energy absorption. But once the adequate number of spot-weld is not met, there may be inefficient bonding between the components of the crashbox, which later affects in appropriate crushing behavior of the structure. Hence the number of spot-welds is highly sensitive towards energy absorption characteristics of the thin-walled structure. Referring towards average thickness, upon an increment of average thickness, the EA develops slowly. When the average thickness approaches an optimal limit, the energy absorption reaches its full capacity. In contrast with the spot-weld number, there is no critical limit for the average thickness to determine the energy absorption. But beyond the optimal limit of the crash-box structure, an increase in the average thickness could lead to failure in the crushing performance of the structure. The thin walls become stiffer and do not yield in progressive crushing, rather it ruptures. In the case of our crash-box model, an average thickness of $2.00 \mathrm{~mm}$, the structure exhibited an undesirable crushing process with failures and ruptures in the geometry.

Figure 11 represents the absolute effect of increased thickness beyond the optimal value. It can be understood, that upon increase in average thickness of the structure, they become unsuitable in executing perfect energy absorption phenomenon. Once the crushing is initiated, the bonded sheets of metal, wear out exhibiting a blown-out failure thereby resulting in a catastrophic effect. Moreover, by carefully examining Figure 10b, it can be stated that the trend of plot between, EA \& Average thickness of the EA value at the failure point, resulted in a drastic increase in energy absorption. As discussed earlier, even though the average thickness is increased beyond the optimal point, it always produces drastic effects in EA values. But that always failed crash-box's functioning. By observing the failure pattern, to arrest the dismantling effect between the sheets of 
metals, increasing the spot-weld number can be considered as an alternative. But the investigation on that criterion didn't serve the purpose. In Figure 11b , the resulting deformation modes corresponds to the crash-box specimen with a maximum number of spot-welds (i.e., 14). Despite increasing the spot-welds, the failure phenomenon remained unchanged. Therefore, we could conclude that optimum average thickness varies according to the physical nature of the crash-box structure and successive optimization methodologies assist us in predicting those design variables. Thus, the optimal selection of design variables such as spot-weld number and avg. thickness varies for different cases of crash-boxes.

\section{Conclusion}

In this research work, the explicit axial impact analysis was carried out upon crash-box structure (Courtesy: Toyota) offered by NHTSA [12] to study the possibilities of improving its crashworthiness. The optimization problem is framed based on the objective of maximizing two influential crashworthiness parameters, EA and CFE. The optimization procedure was performed based on response surface methodology with a central composite design involving full-quadratic polynomials in constructing the regression model. From the RSM results, the multi-objective response optimization was determined by the response optimizer algorithm based on the desirability function. The finite element simulations were preliminarily performed for the default physical configuration to benchmark with the optimized crash-box outcomes. From the optimized design, we could observe that there was an $8.8 \%$ increment in crush force efficiency and approximately $30 \%$ increase in overall energy absorption capacity. Since the physical design parameters were modified for the optimization, the rise in overall mass was still below $6.7 \%$. Ultimately the EA capacity of the structure was increased by $35 \%$, subsequently, the improvement in SEA about $32 \%$ was also well noticed. From the inferences of the FE simulations, the sensitivity of spot-weld number and average thickness in determining the energy absorption of the structure was illustrated. From the validation process, the simulated results were in close alignment with the respective analytical calculations. Hence the better robust design for the crash-box geometry of the Toyota model was proposed which aimed at providing better safety in a crushing phenomenon.

\section{Future scope}

Further researches can be adopted in utilizing the optimized FE model in developing the reduced-order models which can be used in acquiring the crashworthiness parameters for a different combination of physical parameters under low computational cost and time [22]. Hence reduced-order models, can be resourceful in utilizing the system simulation capabilities, to study the sub-system behavior.

\section{Nomenclature}

$\begin{array}{ll}\text { ARAI } & \text { Automotive Research Association of India } \\ \text { COG } & \text { Centre Of Gravity } \\ \text { CCD } & \text { Central Composite Design } \\ \text { CFRP } & \text { Carbon Fiber Reinforced Polymer } \\ \text { DOE } & \text { Deign of experiments } \\ \text { DOF } & \text { Degrees of freedom } \\ \text { Global NCAP } & \text { Global New Car Assessment Program } \\ \text { MOR } & \text { Model Order Reduction } \\ \text { NHTSA } & \text { National Highway Traffic Safety Admin- } \\ & \text { istration } \\ \text { PLINK } & \text { Point Linkage } \\ \text { SPW } & \text { Spot-Weld } \\ \text { THK } & \text { Average Thickness } \\ \text { EA } & \text { Energy absorption (kJ) } \\ \text { SEA } & \text { Specific energy absorption }(\mathrm{kJ} / \mathrm{kg}) \\ \text { CFE } & \text { Crush force efficiency }(\%) \\ P_{m} & \text { Mean crushing load }(k N) \\ M_{o} & \text { Plastic bending moment }(N) \\ \delta & \text { Displacement (mm) } \\ \sigma_{y} & \text { Yield stress of the material }(M P a) \\ P_{\max } & \text { Peak crushing force }(k N) \\ h & \text { Thickness (mm) } \\ c & \text { Average side lengths }(\mathrm{mm}) \\ d & \text { Crush length (mm) } \\ R^{2} & R \text { squared } \\ R_{\text {adj }}^{2} & \text { R squared adjusted. }\end{array}$

Acknowledgments. We sincerely thank ESI group India, for providing the finite element software VPS: Pam-Crash, Visual mesh, and Visual viewer for undertaking this research work. Also, we thank them for providing the academic licensing in aiding the current study and for further works in the near future.

\section{References}

1. N.A.Z. Abdullah, M.S.M. Sani, M.S. Salwani, N.A. Husain, A review on crashworthiness studies of crash box structure, Thin-Walled Struct. 153, 106795 (2020)

2. M. Fontana, A.L. Araujo, J.F.A. Madeira, Optimization of a thin-walled composite crash absorber, Thin-Walled Struct. 155, 106826 (2020)

3. C. Kilıçaslan, Numerical crushing analysis of aluminum foam-filled corrugated single- and double-circular tubes subjected to axial impact loading, Thin-Walled Struct. 96, 82-94 (2015)

4. S. Sarage, M. Agrewale, K.C. Vora, Design and optimization of crash-box of passenger vehicle to enhance energy absorption (2019) https://doi.org/10.4271/2019-01-1435

5. G. Balaji, K. Annamalai, An experimental and numerical scrutiny of crashworthiness variables for square column with V-notch and groove initiators under quasi-static loading, Cogent Eng. 4, 1 (2017)

6. M. Pohlak, J. Majak, M. Eerme, Optimization of car frontal protection system, Int. J. Simul. Multidiscipl. Des. Optim. 1, 31-37 (2007) 
7. S. Ming, Z. Song, T. Li, K. Du, C. Zhou, B. Wang, The energy absorption of thin-walled tubes designed by origami approach applied to the ends, Mater. Des. 192, 108725 (2020)

8. L. Yuan, H. Shi, J. Ma, Z. You, Quasi-static impact of origami crash boxes with various profiles, Thin-Walled Struct. 141, 435-446 (2019)

9. G. Balaji, K. Annamalai, Crushing response of square aluminium column filled with carbon fibre tubes and aluminium honeycomb, Thin-Walled Struct. 132, 667-681 (2018)

10. J. Simpson, Z. Kazanc1, Crushing investigation of crash boxes filled with honeycomb and re-entrant (auxetic) lattices, Thin-Walled Struct. 150, 106676 (2020)

11. Y. Zhang, J. Wang, T. Chen, M. Lu, F. Jiang, On crashworthiness design of double conical structures under oblique load, Int. J. Vehicle Des. 76, 20-45 (2018)

12. NHTSA, Crash Simulation Vehicle Models, (2020) Available at: https://www.nhtsa.gov/crash-simulation-vehicle-models (Accessed 25 October 2020)

13. H. Zdenek, Optimization of source-wire-gas systems for efficient robot welding, Int. J. Simul. Multidiscipl. Des. Optim. 4, 107-116 (2012)

14. P. Hernández, R. Monzon, M. González, B. Pei, E. Winter, G. Ortega Fernando, Lightweight parametric optimisation method for cellular structures in additive manufactured parts, Int. J. Simul. Multisci. Des. Optim. 7 (2016)
15. H. Yue, D. Bassir, H. Medromi, H. Ding, K. Abouzaid, Optimal design of vertical-taking-off-and-landing UAV wing using multilevel approach, Int. J. Simul. Multidisci. Des. Optim. 11, 26 (2020)

16. K. Annamalai, G. Balaji, Numerical investigation of aluminum honeycomb filled high strength steel crash box for the effect of honeycomb physical parameters on crashworthiness constant, ISE 8, 2650-2665 (2018)

17. W. Abramowicz, N. Jones, Dynamic axial crushing of square tubes, Int. J. Impact Eng. 2, 179-208 (1984)

18. G. Balaji, K. Annamalai, Numerical investigation of honeycomb filled crash box for the effect of honeycomb's physical parameters on crashworthiness constants, Int. J. Crashworth. 24, 1-15 (2018)

19. VPS, (Virtual Performance Solution) Solver Reference Manual, ESI Group, Vol1-6, Version 2017.0

20. Y. Xiang, Q. Wang, Z. Fan, H. Fang, Optimal crashworthiness design of a spot-welded thin-walled hat section, Finite Elem. Anal. Des. 42, 846-855 (2006)

21. Y. Liu, Design optimization of tapered thin-walled square tubes, Int. J. Crashworth. 13, 543-550 (2008)

22. Y. Le Guennec, J.-P. Brunet, F.-Z. Daim, M. Chau, Y. Tourbier, A parametric and non-intrusive reduced order model of car crash simulation, Comput. Methods Appl. Mech. Eng. 338, 186-207 (2018)

Cite this article as: Prabhaharan S.A., G. Balaji, Krishnamoorthy Annamalai, Numerical simulation of crashworthiness parameters for design optimization of an automotive crash-box, Int. J. Simul. Multidisci. Des. Optim. 13, 3 (2022) 